\title{
SURFACE-WAVE ATTENUATION AND CRUSTAL ANELASTICITY IN CENTRAL NORTH AMERICA
}

\author{
BY BRIAN J. MITCHELL
}

\section{ABSTRACT}

The southeastern Missouri earthquake of October 21, 1965 generated fundamental- and higher-mode Love and Rayleigh waves which were recorded at numerous North American stations. Love-wave amplitude radiation patterns were determined and found to be consistent with theoretical patterns predicted by a fault-plane solution previously inferred from Rayleigh-wave data.

The radiation patterns were used to estimate the source spectrum and values for Love-wave attenuation coefficients for the mid-continent of North America by a least-squares iterative process. The source spectrum derived from Love-wave amplitudes exhibits a peak at periods between 5 and $9 \mathrm{sec}$ and decreases to a lower DC level at longer periods, in agreement with the source spectrum determined previously for Rayleigh waves. The Love-wave attenuation coefficients decrease rapidly from about $0.0018 \mathrm{~km}^{-1}$ at a period of $4 \sec$ to about $0.0001 \mathrm{~km}^{-1}$ at a period of $20 \mathrm{sec}$. At periods between 20 and $40 \mathrm{sec}$ the values seem to remain nearly constant.

The crust in the mid-continent of North America is characterized by relatively low $Q_{\beta}$ values, 75 to 300 , in its upper portion. At depths between 15 and $20 \mathrm{~km}$, $Q_{\beta}$ increases sharply and decreases again at greater depths. The decrease can be explained as being due to increasing temperature in a homogeneous material, but the sharp increase requires a change in the chemical constitution of the material at mid-crustal depths.

\section{INTRODUCTION}

Seismic surface-wave amplitude radiation patterns have been successfully used to determine earthquake fault-plane solutions. Several authors (e.g. Wu and Ben-Menahem, 1965; Wu, 1968; Canitez and Toksöz, 1971; Mitchell, 1973) have compared observed radiation patterns with those computed according to the theory of Ben-Menahem and Harkrider (1964) to obtain a solution. That theory predicts that surface-wave amplitudes and initial phases generated by earthquakes will vary azimuthally in a manner determined by the depth, strike, dip, and slip angle of the earthquake. The patterns are also model dependent and may vary with frequency and mode number.

In a recent study, Mitchell (1973) used Rayleigh-wave amplitude radiation patterns to determine a fault-plane solution for the southeastern Missouri earthquake of October 21, 1965. Having made that determination, it was then possible to estimate values for the Rayleigh-wave attenuation coefficients and to estimate the shape of the source spectrum. Those estimates were made at periods between 4 and $50 \mathrm{sec}$. An interesting result of that study was that the shape and orientation of the short-period Rayleigh-wave radiation patterns were roughly the same as the area of perceptibility of the earthquake which was determined by Kisslinger and Nuttli (1965). This similarity, combined with lower values of Rayleigh-wave attenuation coefficients in eastern North America as compared with western North America supported the previous conclusions of Necioglu and Nuttli (1971) and Nuttli (1973) that the larger areas of perceptibility of eastern North American earthquakes result from the smaller values of Rayleigh-wave attenuation coefficients in eastern North America. 
This paper presents the results of similar computations for Love waves generated by the October 21, 1965 southeastern Missouri earthquake. Love-wave amplitude radiation patterns are first computed and found to be consistent with those predicted by the favored fault-plane solution of a previous paper by Mitchell (1973). Using that earthquake as a known source, a least-squares fitting of the observed and theoretical patterns yields Love-wave attenuation coefficient values as well as an estimate of the source spectrum.

The region over which the observations of the present study and those of the author's previous paper were made lies in the mid-continental region of North America, between the Rocky Mountains and the Atlantic coast. The relative uniformity of this region allows one to use the surface-wave attenuation coefficients to make a determination of the depth distribution of the quality factor of shear waves in the crust.

\section{DATA}

The locations of the stations which provided Love-wave data for this study are shown in Figure 1. It was hoped that all of the stations which provided Rayleigh-wave data for the author's earlier (1973) paper could be used in this study. It was necessary, however, to have well-recorded wave trains on both horizontal components to measure Love-wave amplitudes, whereas only the single vertical component was necessary for Rayleigh

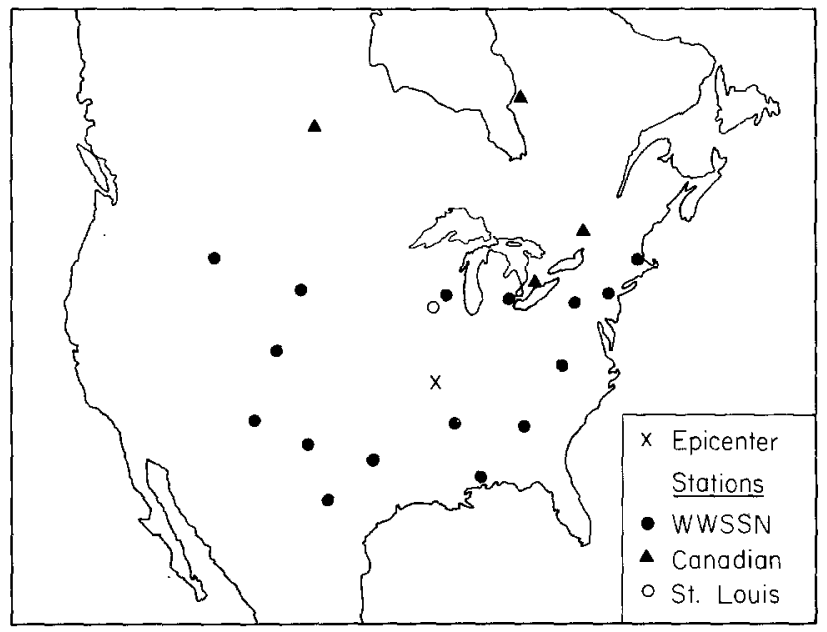

FIG. 1. Epicenter location and seismograph stations from which data were derived.

waves. The chances for instrument malfunctions and unusable records were consequently enhanced, and there were fewer recording sites available for this study than there were for the previous study. The stations selected for both studies were restricted to lie between the eastern fringe of the Rocky Mountains and the Atlantic coast. It is hoped that this region is uniform enough to minimize the adverse effects of focusing and multipathing (McGarr, 1972) and to yield meaningful implications for the earthquake source and for attenuation properties in central North America.

Several stations of the World Wide Standard Seismograph Network (WWSSN), the Seismological Service of Canada, and one station of the St. Louis University network provided Love-wave data for this study. The two horizontal components were digitized at irregular intervals and interpolated to a rate of 4 points per second. The linear trend of each record was removed, and the two were then rotated to obtain the radial and transverse components of ground motion. Seismograms before and after rotation appear in Figure 2. If the rotation is correct, and the surface waves follow a great-circle path 
from the source to the receiver, then the transverse component should contain pure Love waves and the radial component should contain pure Rayleigh waves. The Love waves should arrive earlier than the Rayleigh waves. The recordings at Ann Arbor, Michigan (AAM) exhibit substantial Love-wave energy on the transverse component which arrives before Rayleigh-wave energy on the radial component. The station at State College, Pennsylvania (SCP) recorded very little Love-wave energy.
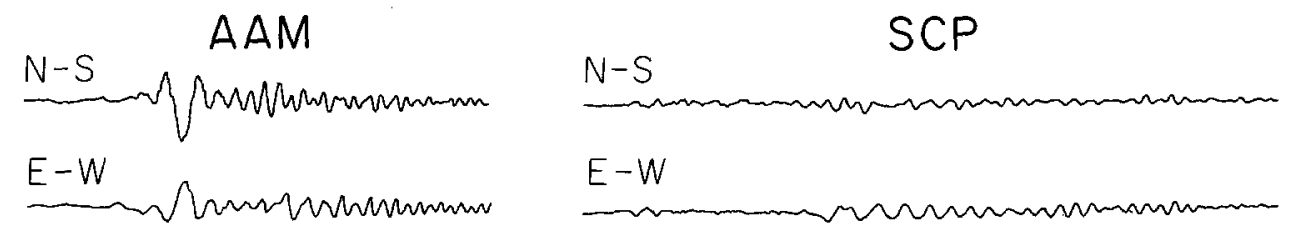

$\mathrm{R}$
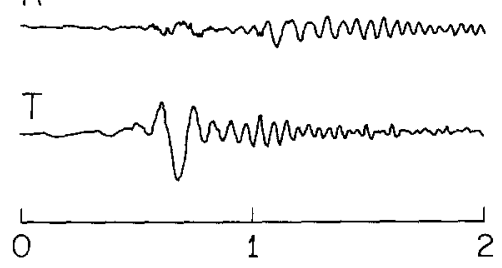

\section{$R$}

T

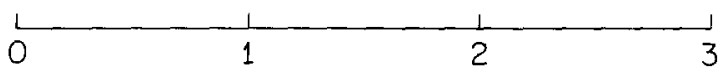

Relative time, min.

FIG. 2. Seismograms recorded near a maximum (AAM) and near a minimum (SCP) in the Love-wave radiation patterns before and after rotation to directions radial $(R)$ and transverse $(T)$ to the path. The transverse records should contain pure Love-wave motion and the radial records should contain pure Rayleigh-wave motion.

The difference between the two recordings can easily be explained by azimuthal variations in the amplitudes generated at the source. The station SCP lies at a null in the pattern and the station AAM lies in a direction at which more Love-wave energy is radiated. The configuration of the Love-wave radiation patterns will be discussed in the next section.

The determination of spectral amplitudes requires a correction for the instrument. A correction can be made if the instrument constants (seismometer free-period, seismometer damping, galvanometer free-period, galvanometer damping, and coupling constant) are known. In his first study, Mitchell (1973) employed the method of Mitchell and Landisman (1969) to determine the instrument constants of the vertical WWSSN seismographs employed in that study. The same values were applied to the two horizontal components at each WWSSN station in the present study. Published values of the instrument constants were used for the stations maintained by the Seismological Service of Canada (Seismological Bulletin, January-December, 1965). Although all of the constants are not available for stations of the St. Louis University network, a correction can be made using published amplitude response curves (Nuttli and McEvilly, 1961).

After correcting for the instrument, the spectral amplitudes can be corrected for attenuation and geometric spreading on a sphere with the equation

$$
A_{c}(\omega)=A(\omega) \mathrm{e}^{\gamma(\omega) x} \sin ^{\frac{1}{2}} \Delta
$$

where

$$
\begin{aligned}
A_{c}(\omega) & =\text { corrected spectrum } \\
A(\omega) & =\text { uncorrected spectrum } \\
\gamma(\omega) & =\text { amplitude attenuation coefficient } \\
x & =\text { epicentral distance in } \mathrm{km} \\
\Delta & =\text { epicentral distance in radians. }
\end{aligned}
$$


The spectral amplitudes at each station were computed by the multiple filter method (Dziewonski, et al., 1969). That method permits the simultaneous determination of group velocities and amplitudes for each mode. An example appears in Figure 3. Contours delineating the fundamental Love mode extend from less than 4 to about $50 \mathrm{sec}$ for this case. The first higher Love mode is poorly developed and obscured by the fundamental mode at periods near $5 \mathrm{sec}$. Interference of the group-velocity curves of the two modes occurs for all stations; consequently, the higher Love-mode data is quite sparse and restricted to periods between 4 and $6 \mathrm{sec}$.

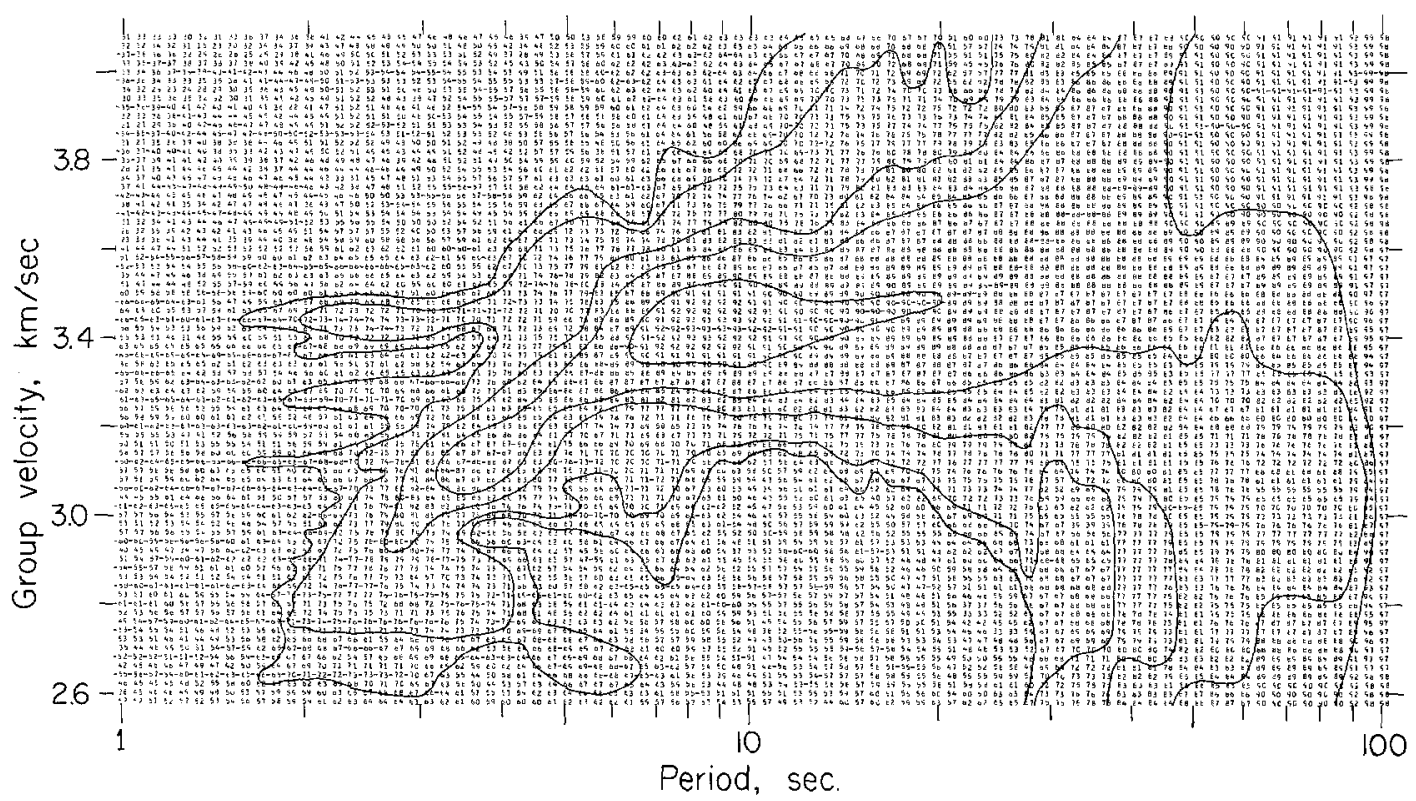

FIG. 3. Contoured amplitudes as a function of period and group velocity obtained by the multiple filter method of Dziewonski et al. (1969). This example results from analysis of the transverse motion recorded at Ann Arbor, Michigan (AAM).

\section{LOVE-WAVE RADIATION}

A focal mechanism solution for the southeastern Missouri earthquake of October 21, 1965 was determined in Mitchell (1973). The solution was achieved by fitting observed amplitude radiation patterns to those computed according to the theory of Ben-Menahem and Harkrider (1964). The favored solution was that of a fault $4 \mathrm{~km}$ deep, being oriented $\mathrm{N} 70^{\circ} \mathrm{E}$, dipping $50^{\circ} \mathrm{S}$, and having a slip vector oriented $85^{\circ}$ downward from the horizontal on the fault face. The derived depth value compares favorably with a depth found previously by using $P n$ arrivals at near ranges (Kisslinger and Nuttli, 1965). Other possible solutions permitted by symmetries in the radiation patterns were excluded by observing $P$-wave first motions or by using published field observations. An alternative solution was also presented, but it provided a much poorer fit to the data than the preferred one.

It was immediately apparent that the observed Love-wave amplitude radiation patterns were consistent with the theoretical patterns predicted by the favored fault-plane solution of the author's earlier (1973) paper. It is a four-lobed pattern, the orientation of which remains unchanged over the entire period range under consideration. A wide range of faultplane solutions, including the alternate one from Mitchell's (1973), previous paper, however, also accord with the Love-wave radiation patterns. Love-wave radiation patterns 
are, therefore, not as useful as Rayleigh-wave patterns for determining the fault-plane solution for this particular earthquake.

Theoretical Love-wave radiation patterns were computed from the equation

$$
A_{t}(\omega)=S_{t}(\omega) k^{1 / 2}|\chi(\theta, h, \omega)| A_{L}(\omega)
$$

where $|\chi(\theta, h, \omega)|$ is the modulus of the complex radiation pattern function, $k$ is the wave number, $A_{L}(\omega)$ is the Love amplitude response, and $S_{t}(\omega)$ can be considered to be the source spectrum (Harkrider, 1970). The form of this equation differs from that for Rayleigh waves only by a factor $\varepsilon_{0}$, the surface ellipticity for Rayleigh waves. The crustmantle model of McEvilly (1964) with an anisotropic mantle was used in all computations.

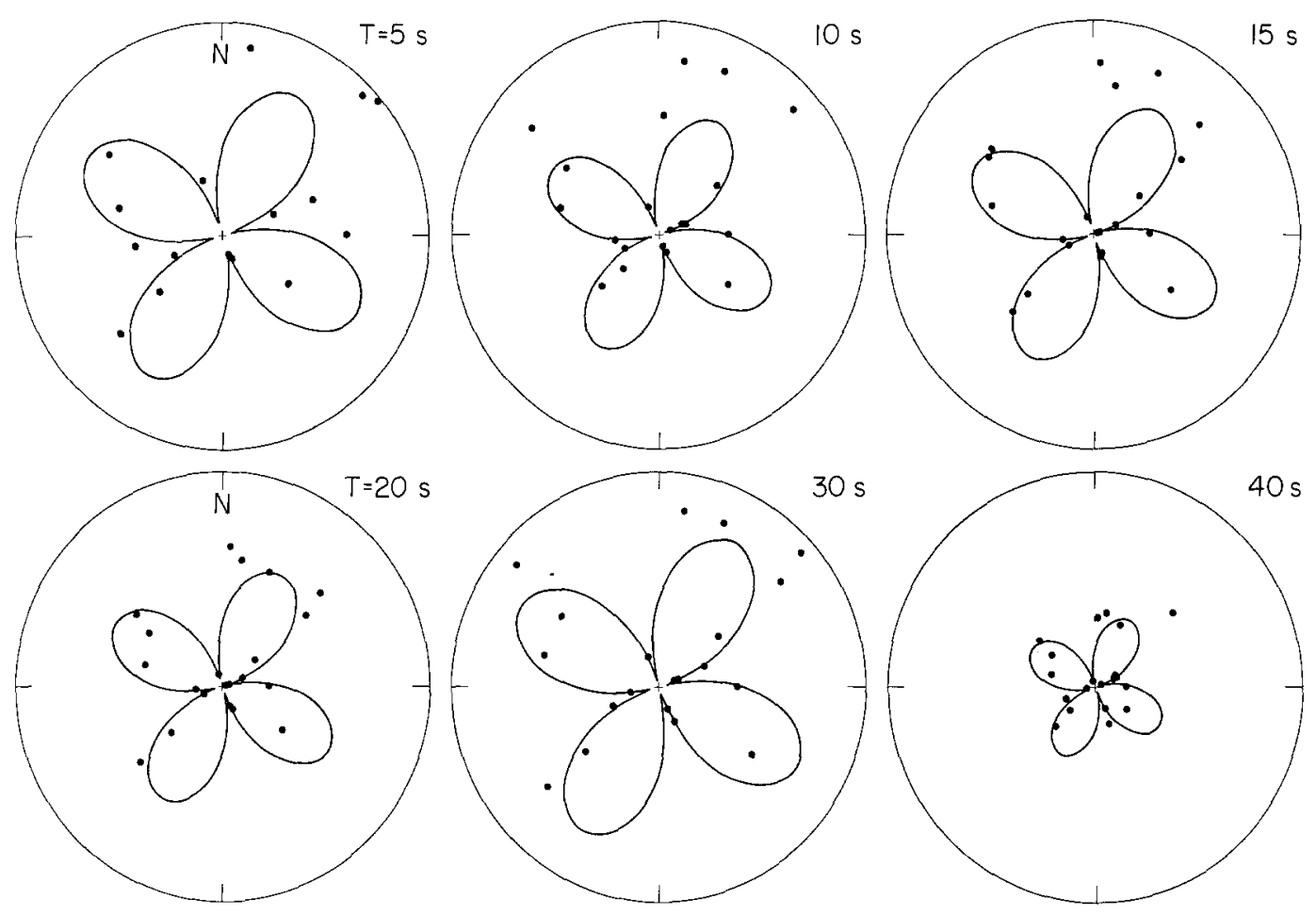

FIG. 4. Comparison of observed fundamental Love-mode amplitudes (dots) with theoretical radiation patterns computed for the preferred fault model of Mitchell (1973) at six periods. The observed amplitudes are corrected for attenuation using the attenuation coefficient values obtained from the best leastsquares fit of the observed and theoretical patterns.

Comparisons of theoretical patterns for the favored fault-plane solution of the author's earlier paper and the observed fundamental Love-wave patterns at six periods appear in Figure 4, and a similar comparison for the first higher Love mode at one period appears in Figure 5. The observed amplitudes were corrected for attenuation using the attenuation coefficient values derived in the following section. Although a fit can be achieved at all periods, the scatter is generally greater than that associated with the Rayleigh-wave patterns previously observed by Mitchell (1973). The amplitudes measured in a northeasterly direction from the source are larger, especially at short periods, than those in other directions. This effect was also noted previously for Rayleigh waves by Mitchell (1973) and attributed to the effect of fault propagation in that direction. 
Following the earlier methods of Mitchell (1973), a least-squares iterative process was used to estimate the source spectrum and values for the Love-wave attenuation coefficients. That paper describes the process in detail, so it will not be repeated here. Source spectra for the fundamental and first higher Love and Rayleigh modes appear in Figure 6. The spectra for the fundamental Love and Rayleigh modes span the period ranges from 4 to 40 and from 4 to $50 \mathrm{sec}$, respectively. They both peak between 5 and $9 \mathrm{sec}$ ard attain a

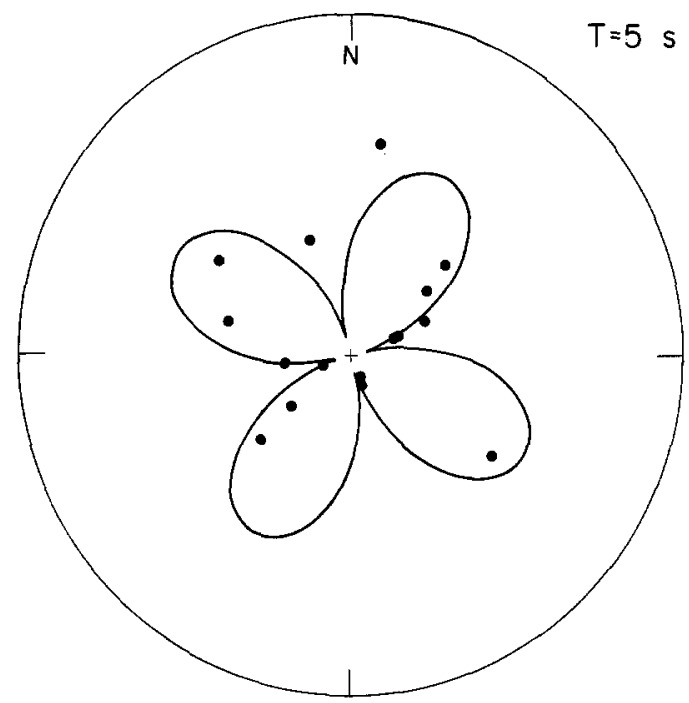

FIG. 5. Comparison of observed higher Love-mode amplitudes with theoretical radiation patterns computed for the preferred fault-plane solution of Mitchell (1973) at a period of $5 \mathrm{sec}$.

lower DC level at longer periods. These spectra appear to lie between the theoretical source spectra predicted by the model of Archambeau (1968) and that of Brune (1970). Archambeau's (1968) model predicts a more prominent peak than that exhibited in Figure 6, whereas Brune's (1970) model predicts no peak at all. If the observed spectra of Figure 6 could be accepted with absolute confidence, they would suggest that the effect of friction along the fault face is greater than that implied by Archambeau's model and less than that implied by Brune's model. Experimental uncertainty in the fault-plane solution and in the assumed velocity model, however, may preclude any definitive statements regarding details of the spectrum at the earthquake source with the limited amount of data.

If all factors have been properly taken into account (fault-plane solution, model, attenuation), the four spectra in Figure 6 should be identical. The spectrum for the first higher Rayleigh mode is, however, substantially higher than the others. This disparity could be most easily reconciled by increasing the value of the surface ellipticity for the higher-mode Rayleigh waves. That factor is not included in the computation of Lovewave spectra and a sample calculation indicates that changing the velocity of the surface layer would change the surface ellipticity value for the higher Rayleigh mode about ten times more than it would change the fundamental mode ellipticity value. Lowering the surface ellipticity value would require the insertion of a low-velocity layer at the surface of McEvilly's (1964) central United States model. Further evidence that such a low-velocity surface layer might be required comes from the observed group-velocity values for both Love and Rayleigh waves. The mean group-velocity values, for both the author's earlier and present studies seem to be slightly lower at most periods than those predicted by the 
model of McEvilly (1964). It is possible that the region studied by McEvilly (1964) is characterized by slightly higher velocities than the broader region included in the present study. Alternatively, it may be possible to explain the lower group velocities with a model that would only slightly change the phase velocities. Group velocities of Love and Rayleigh waves in central North America will be the subject of another study.

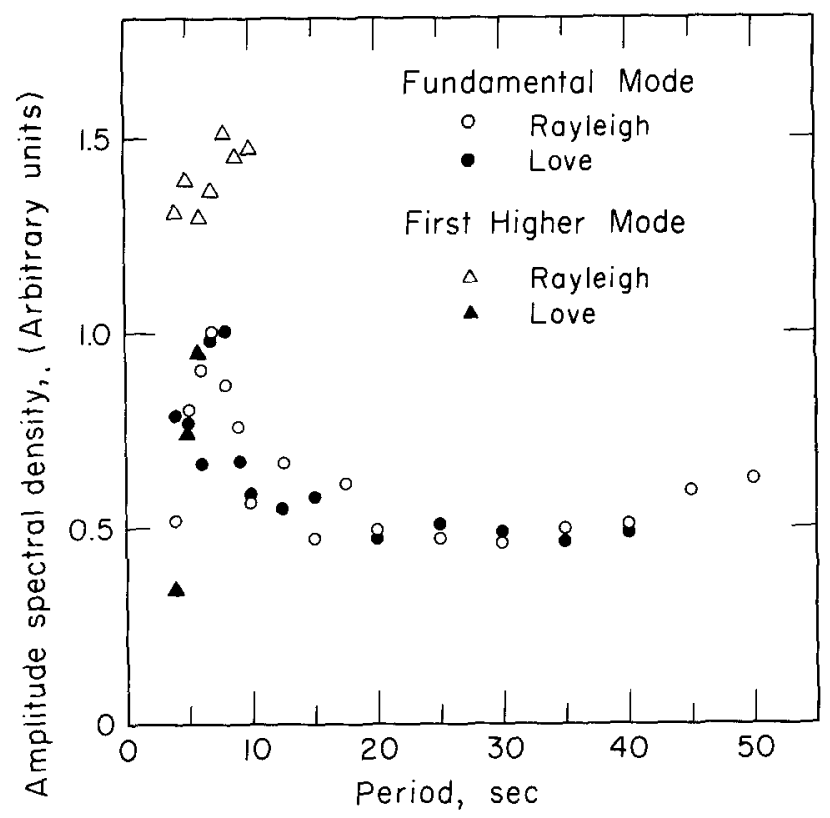

FIG. 6. Source spectra of the fundamental Love, fundamental Rayleigh, and first higher Love and Rayleigh modes derived from a least-squares fitting of observed and theoretical radiation patterns.

\section{ATtENUATION}

Values for the Love-wave attenuation coefficients were determined by the methods discussed by the author in his earlier (1973) paper. They can be considered to be average values for the mid-continent of North America. Since the attenuation coefficients are essentially smoothing operators for the observed radiation patterns, they are not very sensitive to inaccuracies in the determination of the focal mechanism or to small fluctuations from the assumed velocity model. Fundamental Love-mode attenuation coefficients were determined for periods between 4 and $40 \mathrm{sec}$ and first higher Love-mode coefficients were determined for periods between 4 and $6 \mathrm{sec}$. They appear in Figure 7 along with observed values obtained by Ben-Menahem (1965) for a path largely consisting of the Canadian shield, and by Solomon (1972) for the western United States. The values of the latter study were converted from $Q$ values using the equation $\gamma=\pi / U T Q$ with appropriate period $(T)$ and group-velocity $(U)$ values. The western United States attenuation coefficients are substantially higher than those obtained for the more eastern regions of North America at periods greater than $40 \mathrm{sec}$. Fundamental mode values of the present study decrease rapidly from about $0.0018 \mathrm{~km}^{-1}$ at a period of $4 \mathrm{sec}$ to nearly $0.0001 \mathrm{~km}^{-1}$ at a period of $17.5 \mathrm{sec}$. At greater periods, the coefficient values change only slightly. The higher mode coefficients are somewhat lower than those of the fundamental mode, presumably because they sample more deeply within the crust and are less affected by near-surface irregularities and low- $Q$ surface material. 
Figure 8 compares the Love-wave attenuation coefficient values of the present study with the Rayleigh-wave coefficients estimated previously (Mitchell, 1973). The fundamental Love-mode values are higher than the corresponding Rayleigh-wave values at all periods. This combined set of Love- and Rayleigh-wave attenuation data taken over a relatively uniform region provides an opportunity to make estimates of the quality factor distribution of the material in the crust. Although similar determinations have been made for the mantle (Anderson and Archambeau, 1964; Anderson, et al., 1965), crustal anelasticity determinations using surface waves have been restricted to average values

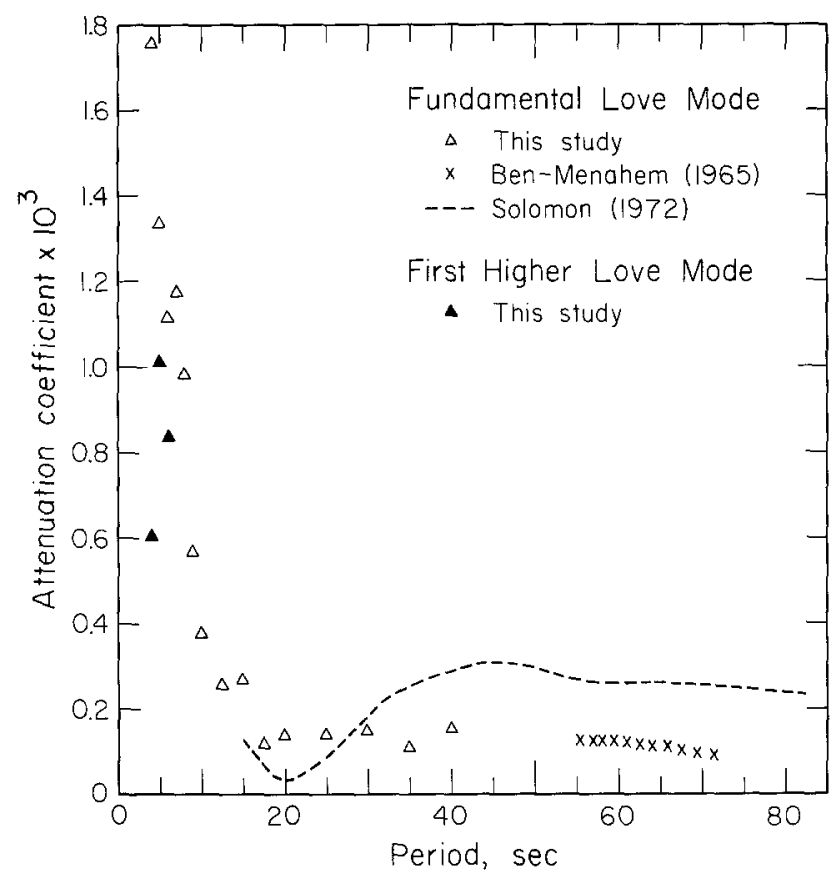

FIG. 7. Amplitude attenuation coefficients for fundamental- and first higher-mode Love waves determined for North American paths. Values obtained in the present study, and those determined by BenMenahem (1965) pertain to the region east of the Rocky Mountains and the values of Solomon (1972) pertain to the region west of the Rocky Mountains.

(Press, 1964). The reasons for this deficiency of information are well known; instrumental effects, source characteristic's, scattering and local geology, factors which make meaningful amplitude studies at all periods difficult, have especially adverse consequences for short-period waves. Attempts have been made by the author, however, previously (1973) and in the present study to correct for the first two of these effects, and it is hoped that the latter two are minimized by making many observations within a relatively uniform region. Anderson et al. (1965) present a theory for the attenuation of dispersed waves. Quality factors for Love $\left(Q_{L}\right)$ and Rayleigh $\left(Q_{R}\right)$ waves may be written

$$
\begin{aligned}
Q_{L}^{-1} & =\sum_{l=1}^{N}\left(\frac{\partial Q_{L}^{-1}}{\partial Q_{\beta l}}\right)_{k} Q_{\beta l}^{-1}=\sum_{l=1}^{N}\left(\frac{U_{L} \beta_{l}}{C_{L}^{2}} \frac{\partial C_{L}}{\partial \beta_{l}}\right)_{k \rho} Q_{\beta l}^{-1} \\
Q_{R}^{-1} & =\sum_{l=1}^{N}\left[\left(\frac{\partial Q_{R}^{-1}}{\partial Q_{\alpha l}^{-1}}\right) Q_{\alpha l}^{-1}+\left(\frac{\partial Q_{R}^{-1}}{\partial Q_{\beta l}^{-1}}\right) Q_{\beta l}^{-1}\right]_{k} \\
& =\sum_{l=1}^{N}\left(\frac{U_{R} \alpha_{l}}{C_{R}{ }^{2}} \frac{\partial C_{R}}{\partial \alpha_{l}}\right)_{k \rho \beta} Q_{\alpha l}^{-1}+\sum_{l=1}^{N}\left(\frac{U_{R} \beta_{l}}{C_{R}{ }^{2}} \frac{\partial C_{R}}{\partial \beta_{l}}\right)_{k \rho \alpha} Q_{\beta l}^{-1}
\end{aligned}
$$

where $\alpha$ and $\beta$ are compressional- and shear-wave velocities, $Q_{\alpha}$ and $Q_{\beta}$ are the quality 
factors for compressional and shear waves, $C_{L}$ and $C_{R}$ are Love- and Rayleigh-wave phase velocities, and 1 is the layer index. The subscripts $k, \alpha, \beta$, and $\rho$ refer to wave number, compressional velocity, shear velocity, or density, being held constant. Recent studies (e.g. Backus and Gilbert, 1970; Der and Landisman, 1972; Jordan, 1972) have permitted the consideration of errors and resolution in inverse problems. The present study follows methods developed by Jordan (1972) for inverting inaccurate data and investigating the resolvability of features in the resulting model. Details of the theory

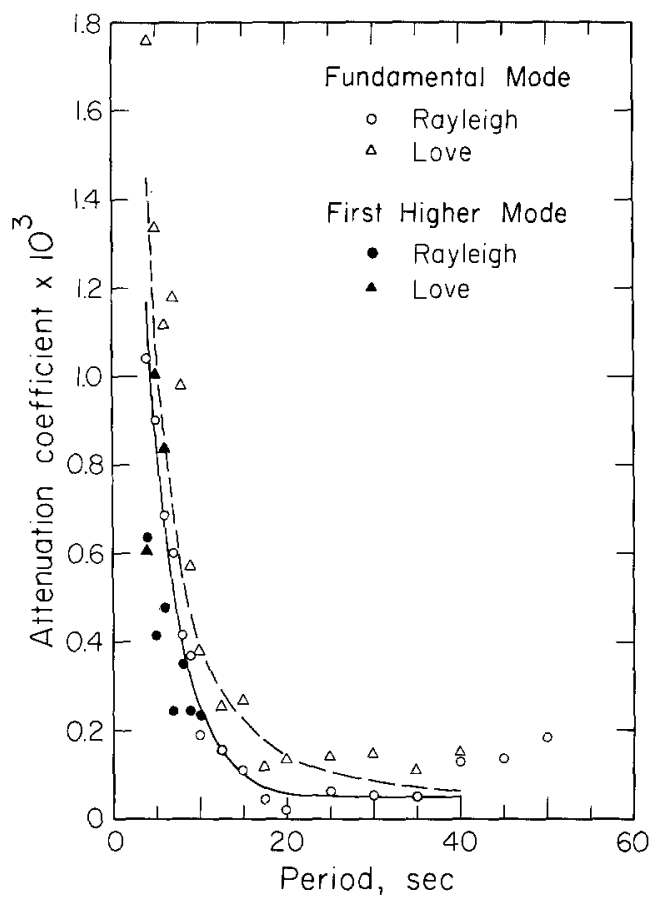

FIG. 8. A comparison of Love-wave attenuation coefficient values with those values previously derived for Rayleigh waves. The solid line represents theoretical values for fundamental mode Rayleigh waves and the dashed line represents theoretical values for fundamental mode Love-waves which formed the closest fit to the data from among all of the derived models.

appear in Jordan (1972) and Alewine and Jordan (1973). The equations from Jordan (1972) which are pertinent to the present study are

$$
\begin{gathered}
\delta m=W \cdot A^{*}\left(A \cdot W \cdot A^{*}+\eta C_{n n}\right)^{-1} \delta d \\
K=W \cdot A^{*}\left(A \cdot W \cdot A^{*}+\eta C_{n n}\right)^{-1} A
\end{gathered}
$$

where $A$ is the matrix of partial derivatives computed for the assumed velocity model, $W$ is a weighting vector, each element of which is taken to be the inverse of a layer thickness in the present study, $C_{n n}$ is a noise matrix which includes the errors assigned to each observation, $\eta$ is a factor by which we can adjust the effect of measurement error, and an asterisk denotes the transpose of a matrix. Small values of $\eta$ enable us to resolve detail in our model, but reduce the reliability of our estimate. This tradeoff between resolvability and reliability was first pointed out by Backus and Gilbert (1970). Equation (4) determines perturbations $(\delta m)$ to a starting model and $\delta d$ is the column matrix of the differences between the observations and values predicted by the starting model. For a linear inversion process like that of the present study, a starting model need not be assumed, and $\delta m$ can be replaced by $m$ and $\delta d$ by $d$ in (4). Equation (5) computes averaging kernels $(K)$ which permit an estimate of resolvability for features in any model. 
The present application solves equations (3) for the intrinsic quality factors $Q_{\alpha}$ and $Q_{\beta}$. The results are complicated by the fact that effects other than intrinsic anelasticity affect the observations. It is necessary in the present determination to ignore those effects if an estimate of the crustal $Q$ distribution is to be made. The observed surface-wave quality factors, $Q_{L}$ and $Q_{R}$, derived from the attenuation coefficients, and the phase-velocity partial derivatives for the anisotropic model of McEvilly (1964) were used in the inversion. The upper portion of the original seven-layer model of McEvilly (1964) was divided so that it consists of twenty $1-\mathrm{km}$ thick layers, twenty-one $2-\mathrm{km}$ thick layers, and five 4-km thick layers. Partial derivatives were computed according to methods discussed by Harkrider (1968).

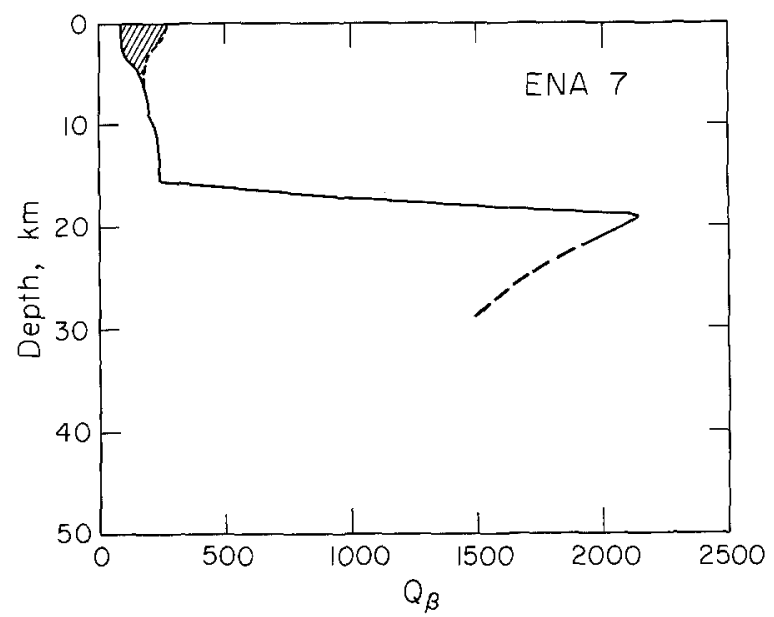

FIG. 9. Model ENA7 for the distribution of the shear wave quality factor $\left(Q_{\beta}\right)$ in the crust of midcontinental North America. Great confidence should not be placed on the numerical values attained by this model. The numerical values will vary greatly, depending on the magnitudes of the errors assigned to each observation. The major features of this model (low surface values, a dramatic increase, and a deeper decrease) are characteristic of all of the inversion attempts. The dashed line indicates the portion of the model where resolvability is considered poor.

The model resulting from the inversion process is nonunique and depends on the relative magnitudes of the errors assigned to the observations. It seems reasonable to assign the highest errors to the shortest periods where scattering would have the greatest effect, and to the longest periods where the smallest amplitudes were recorded. Observations over the central part of the period range should be more reliable than those near the end points. The Rayleigh-wave data should be more reliable than the Love-wave data, since more Rayleigh-wave observations are available, and since they exhibit less scatter on the radiation pattern plots.

It was not possible to obtain a meaningful $Q_{\alpha}$ model with the data of this study. However, a $Q_{\beta}$ model for the crust of the North American mid-continent appears in Figure 9. Great confidence should not be given to the numerical values of this model, since they can be made to vary by large amounts by changing the errors assigned to the observations. $Q_{R}$ and $Q_{L}$ are particularly insensitive to changes in high $Q_{\beta}$ values. Although details of the $Q_{\beta}$ distribution may vary with different inversion attempts, the major features of the ENA7 model in Figure 9 occur with every inversion. Relatively low values, 75 to 300 , persist to depths between 15 and $20 \mathrm{~km}$. The upper portion of the model, indicated by the shaded area, is poorly determined because of the lack of data at periods shorter than $4 \mathrm{sec}$. At mid-crustal depths, $Q_{\beta}$ increases sharply to values as great as 2,000 or more. The details of this increase must remain a matter of conjecture. Some solutions 
contained a more rapid increase while others were more moderate than that of ENA7. The increase was dramatic, however, in every case. Beneath the rapid increase, the $Q_{\beta}$ values show an immediate but more gradual decrease.

One set of attenuation coefficient values derived in this study is compared with the observed fundamental Love- and Rayleigh-mode coefficients in Figure 8. This is the closest fit which was achieved. There are more disparate Love-wave points since larger errors were assigned in that case. A better fit to the Love-wave data can be achieved, but larger disparities would then result for the Rayleigh waves. At short periods, the observed Love-wave attenuation is somewhat greater than the predicted values. It is possible that this is due to scattering from lateral inhomogeneities which may affect Love waves more than Rayleigh waves. The trend of the observed Love-wave attenuation again differs from the predicted values at periods greater than $25 \mathrm{sec}$. Several reasonsmay be invoked to explain this disparity at the larger periods: (1) $Q$ anisotropy might exist in the crust, (2) scatter in the Love-wave data which is greater than that for the Rayleigh waves might prevent a good estimate of the Love-wave attenuation coefficients, (3) the assumed central United States velocity model of McEvilly (1964) might not be exactly appropriate for the present study, and (4) branch cut contributions which have not been taken into account in the computations of this study might very well be important for Love waves at the periods in question (D. V. Helmberger, personal communication). Possibility (1) is considered to be unlikely, and the fact that the observed values are consistently high rather than scattered argues against (2). Difficulties with (3) may take various forms. The average velocities over the region of the present study may differ slightly from those of the smaller region studied by McEvilly (1964) and which was assumed to prevail over the entire region of the present study. Second, McEvilly's Love-wave velocities may possibly be in error as he and Thatcher and Brune (1969) have suggested. This provides an additional reason for giving greater weight to the Rayleigh than to the Love-wave attenuation values in this study. Possibility (4) cannot be investigated at the present time, but it is apt to be important.

Figures 10 and 11 present averaging kernels for the quality factors of shear waves and compressional waves, respectively. The left-hand side of each figure shows the kernels for the quantity under consideration and the right-hand side illustrates tradeoffs with the other quantity. The depths for which the kernels are computed appear beside each plot, and are indicated by a short vertical line on each abscissa. Narrow peaks, localized at the proper depth, indicate a high degree of resolution, and broad peaks indicate poor resolution. The kernels for $Q_{\beta}$ in Figure 10 indicate that the averaging is well localized at shallow depths. It becomes more poorly localized with increasing depth, and meaningful information is probably limited to depths only slightly greater than $20 \mathrm{~km}$. Tradeoffs with near-surface $Q_{\alpha}$ values complicate the results at all depths. The kernels of Figure 11 show no well-localized averaging at any depth, and suggest that no meaningful estimates of $Q_{\alpha}$ can be made.

\section{INTERPRETATION}

Energy dissipation, or anelasticity, is more sensitive to changes in crystalline structure due to temperature and phase change than elasticity (Anderson et al., 1965). For this reason, it is interesting to speculate on physical mechanisms which might produce the features of a model like that in Figure 9. The simplest approach is to assume that the crust is homogeneous and that $Q$ varies only with temperature $(T)$ and pressure $(P)$. This mechanism can be described by the equation

$$
Q^{-1}(T, P)=Q_{0}^{-1} \exp \left[E^{*}\left(T-T_{0}\right) / R T_{0} T\right] \cdot \exp \left[\left(P_{0}-P\right) V^{*} / R T\right]
$$


where $E^{*}$ and $V^{*}$ are the activation energy and activation volume appropriate for the mechanism, and $Q_{0}{ }^{-1}, P_{0}$, and $T_{0}$ refer to reference values of quality factor, pressure, and temperature. The decrease in $Q$ in the lower part of the model can easily be explained with this mechanism by assigning $E^{*}$ values between 2.0 and $5.0 \mathrm{kcal} / \mathrm{mole}$, and $V^{*}$ values between 0.1 and $0.5 \mathrm{~cm}^{3} /$ mole, and using the eastern United States temperature distribution of Blackwell (1971).
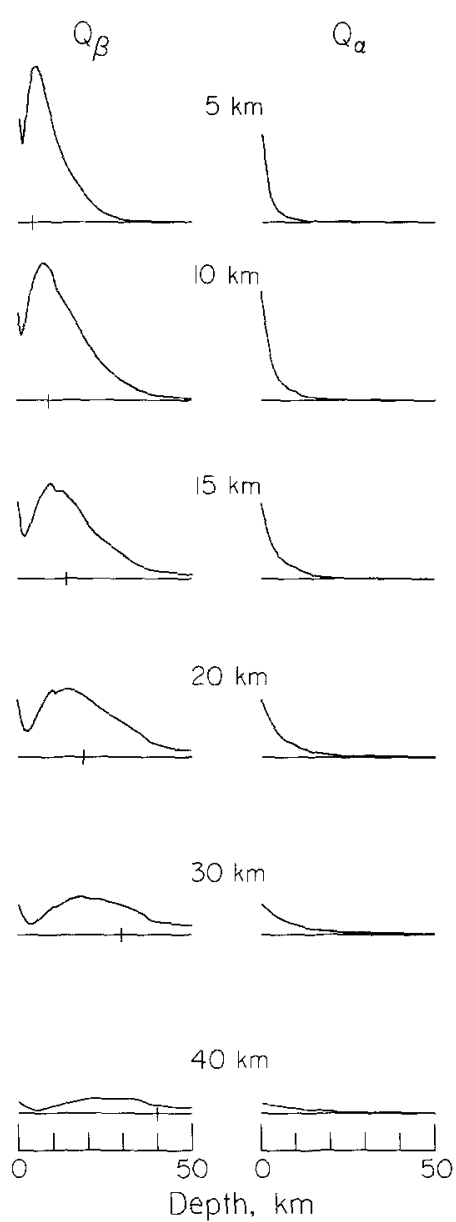

FIG. 10. Averaging kernels for $Q_{\beta}$.

The sharp increase in $Q_{\beta}$ at depths between 15 and $20 \mathrm{~km}$ in model ENA7 cannot be explained with a homogeneous crustal model. The model seems to infer a change in the chemical constitution of the crust at that depth. Seismic refraction studies in the midcontinent of North America commonly yield models in which the velocity increases from between 5.9 and $6.2 \mathrm{~km} / \mathrm{sec}$ to between 6.6 and $7.0 \mathrm{~km} / \mathrm{sec}$ at similar depths. This can quickly be seen from the fence diagram compilation of crustal models for the central and eastern United States presented by Healy and Warren (1969). Model ENA7 suggests a major property change at mid-crustal depths in the mid-continent of North America. It lends support to early ideas of a "Conrad" discontinuity separating rock with different chemical properties. It must be remembered, however, that model ENA7 was constructed from average attenuation observations over a broad region, and includes the effects of scattering as well as of intrinsic anelasticity. 


\section{CONCLUSIONS}

The observed amplitudes of fundamental- and first higher-mode Love waves from the southeastern Missouri earthquake of October 21, 1965 exhibit four-lobed patterns at all periods. They are compatible with theoretically predicted patterns of a fault model derived previously from Rayleigh-wave radiation patterns. The favored solution is that of a fault $4 \mathrm{~km}$ deep, oriented at an azimuth of $\mathrm{N} 70^{\circ} \mathrm{E}$, dipping $50^{\circ} \mathrm{S}$, and having a slip vector oriented $85^{\circ}$ downward from the horizontal on the fault face. The patterns are

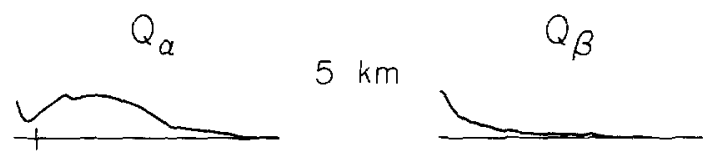

$10 \mathrm{~km}$
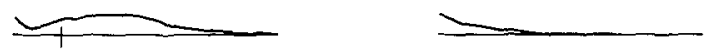

$15 \mathrm{~km}$
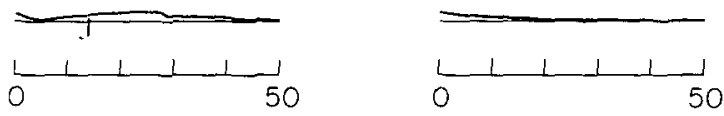

Depth, $\mathrm{km}$

FIG. 11. Averaging kernels for $Q_{\alpha}$

asymmetric with the largest amplitudes occurring at stations toward the northeast. This accords with asymmetries previously observed in the Rayleigh-wave patterns which were attributed to the propagation of the fault from southwest to northeast.

It is possible to make estimates of the source spectrum and the Love-wave attenuation coefficient at each period using the earthquake as a known source. The source spectrum derived from the Love-wave amplitudes contains a peak at periods between 5 and $9 \mathrm{sec}$ and decreases to a lower DC level at longer periods. The agreement with the source spectrum previously derived from Rayleigh waves adds support for the previously derived fault-plane solution. The Love-wave attenuation coefficient values are somewhat larger than the previously derived Rayleigh-wave attenuation coefficients. They decrease rapidly at periods between 4 and $20 \mathrm{sec}$ and seem to assume nearly constant values at greater periods.

Knowledge of the Rayleigh and Love-wave quality factors, $Q_{R}$ and $Q_{L}$, permits a determination of the distribution of the shear-velocity quality factor, $Q_{\beta}$, with depth in the crust. $Q_{\beta}$ values are relatively low, 75 to 300 , in the upper crust, increase dramatically at depths between 15 and $20 \mathrm{~km}$, and then decrease at a relatively rapid rate. The decrease can be explained as a direct result of increasing temperature with depth in a homogeneous material, but the rapid increase seems to require a change in the chemical constitution of the crust at intermediate depths. 


\section{ACKNOWLEDGMENTS}

I am grateful to Drs. Don L. Anderson, Charles B. Archambeau, David G. Harkrider, Donald V. Helmberger, and to Mr. Ralph W. Alewine for helpful discussions on aspects of this paper. Dr. Harkrider permitted me to use his suite of surface-wave computation programs, Dr. Adam Dziewonski provided me with a copy of his multiple filter program, and Mr. Alewine allowed me to use an adaptation of his inversion program for this study. The program for rotating digitized seismograms used in this study was written by Mr. James H. Whitcomb. Dr. William Stauder furnished seismograms recorded by the St. Louis University network. Dr. Anderson, Dr. Harkrider, and Mr. Alewine critically read the manuscript.

This research was supported by the Advanced Research Projects Agency of the Department of Defense and was monitored by the Air Force Office of Scientific Research under Contract F44620-72-C-0078.

\section{REFERENCES}

Alewine, R. W. and T. H. Jordan (1973). Stochastic inversion of earthquake static displacement fields, Bull. Seism. Soc. Am. (in press).

Anderson, D. L. and C. B. Archambeau (1964). The anelasticity of the earth, J. Geophys. Res. 69, 20712084.

Anderson, D. L., A. Ben-Menahem, and C. B. Archambeau (1965). Attenuation of seismic energy in the upper mantle, J. Geophys. Res. 70, 1441-1448.

Archambeau, C. B. (1968). General theory of elastodynamic source fields, Rev. Geophys. 6, 241-288.

Backus, G. and F. Gilbert (1970). Uniqueness in the inversion of inaccurate gross earth data, Phil. Trans. Roy. Soc. (London), Ser. A, 266, 123-192.

Ben-Menahem, A. (1965). Observed attenuation and $Q$ values of seismic surface waves in the upper mantle, J. Geophys. Res. 70, 4641-4651.

Ben-Menahem, A. and D. G. Harkrider (1964). Radiation patterns of seismic surface waves from buried dipolar point sources in a flat stratified earth, J. Geophys. Res. 69, 2605-2620.

Blackwell, D. D. (1971). The thermal structure of the continental crust, The Structure and Physical Properties of Earth's Crust, Am. Geophys. Union Monograph 14, 169-184.

Brune, J. N. (1970). Tectonic stress and the spectra of seismic shear waves from earthquakes, J. Geophys. Res. 75, 4997-5009.

Canitez, N. and M. N. Toksöz (1971). Focal mechanism and source depth of earthquakes from bodyand surface-wave data, Bull. Seism. Soc. Am. 61, 1369-1379.

Der, Z. A. and M. Landisman (1972). Theory of errors, resolution, and separation of unknown variables in inverse problems, with application to the mantle and the crust in southern Africa and Scandinavia, Geophys. J. 27, 137-178.

Dziewonski, A., S. Bloch, and M. Landisman (1969). A technique for the analysis of transient seismic signals, Bull. Seism. Soc. Am. 59, 427-444.

Harkrider, D. G. (1968). The perturbation of Love wave spectra, Bull. Seism. Soc. Am. 58, 861-880.

Harkrider, D. G. (1970). Surface waves in multi-layered elastic media. Part II. Higher mode spectra and spectral ratios from point sources in plane layered earth models, Bull. Seism. Soc. Am. 60, 1937-1987.

Healy, J. H. and D. H. Warren (1969). Explosion seismic studies in North America, The Earth's Crust and Upper Mantle, Am. Geophys. Union Monograph 13, 208-220.

Jordan, T. H. (1972). Estimation of the radial variation of seismic velocities and density in the Earth, Ph.D. Thesis, California Institute of Technology, 199.

Kisslinger, C. and O. W. Nuttli (1965). The earthquake of October 21, 1965 and precambrian structure in Missouri, Earthquake Notes 36, 32-36.

McEvilly, T. V. (1964). Central U.S. crust-upper mantle structure from Love- and Rayleigh-wave phasevelocity inversion, Bull. Seism. Soc. Am. 54, 1997-2015.

McGarr, A. (1972). Comments on some papers concerning amplitudes of seismic surface waves, $J$. Geophys. Res. 77, 3823-3826.

Mitchell, B. J. (1973). Radiation and attenuation of Rayleigh waves from the southeastern Missouri earthquake of October 21, 1965, J. Geophys. Res. 78, 886-899.

Mitchell, B. J. and M. Landisman (1969). Electromagnetic seismograph constants by least-squares inversion, Bull. Seism. Soc. Am. 59, 1335-1348.

Necioglu, A. and O. W. Nuttli (1971). Surface-wave attenuation in the United States east of the Rocky Mountains (Abstract), Trans. Am. Geophys. Union 52, 285.

Nuttli, O. W. (1973). Seismic wave attenuation and magnitude relations for eastern North America, $J$. Geophys. Res. 78, 876-885. 
Nuttli, O. W. and T. V. McEvilly (1961). The response characteristics of the long period seismographs of the Saint Louis University network, Earthquake Notes 32, 27-36.

Press, F. (1964). Seismic wave attenuation in the crust, J. Geophys. Res. 69, 4417-4418.

Seismological Bulletin, January-December, 1965 (1966). Seismological Service of Canada, Dominion Observatory, 354.

Solomon, S. C. (1972). Seismic-wave attenuation and partial melting in the upper mantle of North America, J. Geophys. Res. 77, 1483-1502.

Thatcher, W. and J. N. Brune (1969). Higher mode interference and observed anomalous apparent Love wave phase velocities, J. Geophys. Res. 74, 6603-6611.

Wu, F. T. (1968). Parkfield earthquake of June 28, 1966: magnitude and source mechanism, Bull. Seism. Soc. Am. 58, 689-709.

Wu, F. T. and A. Ben-Menahem (1965). Surface wave radiation pattern and source mechanism of the September 1, 1962, Iran earthquake, J. Geophys. Res. 70, 3943-3949.

\section{SEISMOLOGICAL LABORATORY}

CALIFORNIA INSTITUTE OF TECHNOLOGY

Pasadena, California 91109

Contribution No. 2247, Division OF

Geological and Planetary Sciences

Manuscript received November 21, 1972 